M. A. Yazdanpanah Jahromi, S. Farahat, S. M. Barakati / TJ MCS Vol .5 No. 2 (2012) 134-145

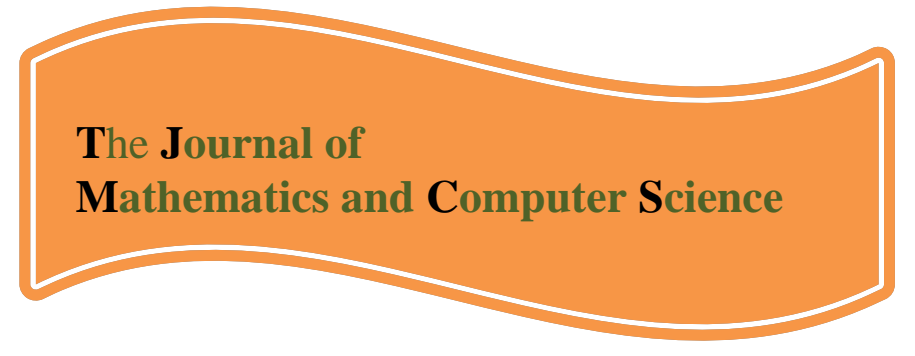

Available online at

http://www.TIMCS.com

The Journal of Mathematics and Computer Science Vol .5 No.2 (2012) 134-145

\title{
A Novel Sizing Methodology Based on Match Evaluation Method for Optimal Sizing of Stand-Alone Hybrid Energy Systems Using NSGA-II
}

\author{
Mohammad Ali Yazdanpanah Jahromi \\ Department of Mechanical Engineering, University of Sistan and Baluchestan, Zahedan, Iran \\ M.yazdanpanah.j@gmail.com \\ Said Farahat \\ Department of Mechanical Engineering, University of Sistan and Baluchestan, Zahedan, Iran \\ Farahat@hamoon.usb.ac.ir \\ Seyed Masoud Barakati \\ Department of Power Electronic Engineering, University of Sistan and Baluchestan, Zahedan, Iran \\ smbaraka@ece.usb.ac.ir
}

Received: February 2012, Revised: November 2012

Online Publication: December 2012

\begin{abstract}
Wind and solar energy technologies offer clean and renewable energy sources, and are essential components of sustainable energy future. The current paper presents a new methodology for size optimization of stand-alone Wind/PV energy systems. The principal objective of this study is to maximize the electricity match rate between demand and supplies, able to accomplish the energy requirements of a given load distribution, for a specific site. Mathematical models of hybrid components are exploited to estimate the total output power using solar radiation, temperature and wind speed data, collected on the site of Zabol, located in Sistan and Baluchestan, Iran. Then, a new methodology has been proposed which can obtain the optimal size of each hybrid component. The objective functions are considered based on supply/demand match evaluation criteria, minimizing the inequality coefficient (IC) and also maximizing the correlation coefficient (CC), simultaneously. The elitist non-dominated sorting genetic algorithm (NSGA-II), which is one of the multi-objective evolutionary algorithm (MOEA), have been employed for a hybrid stand-alone renewable energy power system (Wind/PV) to find the optimal size of each components. The Pareto-optimal solution is obtained in order to have higher-level decision. The designers can select the best configuration among the Pareto set which fits their desire.
\end{abstract}

Keywords: Hybrid Wind/PV systems; multi-objective optimization; sizing method; electricity match rate

2010 Mathematics Subject Classification: Primary 54A40; Secondary 46 S40. 


\section{Introduction.}

The world has a substantial need for alternative energy resources because of the prospect of fossil fuel depletion, increasing population, and increasing energy demand. The assumption is that the supplies of fossil fuels will not be sufficient to satisfy the demand in the future. Hence the electrical power generation has entered into a new phase of evolution. Wind and solar energy technologies are considered as promising power generating resources which are clean, abundant, free, and environment friendly. These two sources have almost complementary power production characteristics. In other words, wind speed is usually more when the sunlight is low and vice versa. Therefore, wind power and photovoltaic (PV) driven stand-alone systems have become one of the most promising ways to overcome the electricity load demand of several off-grid consumers worldwide. A drawback of the mentioned energy options is their unpredictable nature and dependence on weather and climatic conditions. Therefore, these systems, acting alone, have poor reliability of generation and low efficiency. In order to have a practical power system, hybrid power systems is used. M. Vafaei et al. confirm that hybrid stand-alone electricity production systems are usually more reliable and less costly than systems that use only single source of energy [1]. The hybrid system studied in this paper also uses wind turbines and PV array. The stochastic nature characteristic of hybrid components makes them highly nonlinear. In order to have reliable electricity from a hybrid renewable energy system at an economical price, its design must also be optimal in term of operation and components selection. Thus, an optimum sizing method is quite necessary to have an efficient and economical hybrid renewable energy. The computation power of modern computers is increasing dramatically. Hence the computer-based simulation and optimization have received more and more attention, and becoming an important tool for the design of the power systems requiring a detailed analysis. Several methodologies have been developed in this sense and have been reported in the literature. Proper design of stand-alone renewable power system by maximizing the power reliability and cost minimization has been considered a lot in recent years [2-7]. Some others optimized the hybrid power system based on minimization of $\mathrm{CO}_{2}$ emission and levelized cost of energy (LCE) [8]. R. Luna-Rubio reviewed different sizing methodologies developed in recent years [9]. The optimization procedure can be done in different methods. Optimization of Wind/PV hybrid power system with particle swarm optimization (PSO) algorithm for having higher capacity and faster search efficiency is done in [10]. J. Dhillon proposed the NSGA-II algorithm to minimize simultaneously the total system real power loss in transmission network and cost by satisfying power balance equation [11]. A multi-objective design of hybrid systems by minimizing the total cost, pollutant, emission and unmet load is presented in [12].

In order to have an optimum hybrid power generation system which is economical and efficient, sizing optimization method is necessary. Optimum match design will guarantee the lowest investment and optimal using of hybrid energy resources. The contribution of this paper is to propose a new methodology for designing optimal Wind/PV hybrid systems, somehow to maximize the electricity match rate between supplies and demand. The methodology developed in this work was applied using the solar radiation, the temperature and the wind speed collected in the site of Zabol located in the Sistan and Baluchestan, Iran. Inequality coefficient (IC) and correlation coefficient (CC) together, are the math rate criteria in this optimization process. The elitist nondominated sorting genetic algorithm (NSGA-II) is applied for a Wind/PV hybrid system. The decision variables included in this optimization process are the number of PV modules and the number of wind turbines. This algorithm selects the optimal sizing of stand-alone photovoltaicwind generator system with the help of genetic algorithm (GA). GA is the most suitable algorithm in term of global optimization, particular nature of renewable energy and particular problem of auto 
sizing. To have higher-level decision, the Pareto-optimal solution is obtained. The designers can select the best configuration among the Pareto set which fits their desire.

The first step consists of mathematical modeling of hybrid components. Optimization procedure of this hybrid system according to IC and CC concepts is the second step. By applying these two steps to a proposed Wind/PV hybrid system, optimal configuration which can meet the maximum match rate between supplies and demand are obtained.

\section{Modeling of the hybrid system components}

The wind turbine and PV module work together to meet the load demand. Mathematical modeling of the hybrid components is an important step and should be done before any phase of optimal sizing. It helps to estimate the total output power of hybrid system. Various techniques are developed. A brief description for modeling of Wind/PV system is shown in forthcoming subsection. The mathematical modeling in this subsection are from reference [13].

\subsection{Model of PV generator}

The PV generator performance is highly affected by the solar irradiation and the PV generator temperature. The output power of a PV panel can be calculated using the following equation. In order to have higher efficiency for PV panels, the modeling of maximum power point tracking (MPPT) controller has been considered in the simulation of PV array performance. This model can predict the output power of PV panel in different temperatures and various irradiation levels. The average insolation profile and the solar module specification at standard test condition (STC) for the proposed PV module used as model inputs, are given in Figure 1 and TABLE I, respectively. The power production of a $\mathrm{PV}$ panel is given as:

$$
\begin{aligned}
& \mathrm{I}(\mathrm{V})=\frac{I x}{1-\exp \left(-\frac{1}{\mathrm{~b}}\right)} \cdot\left[1-\exp \left(\frac{V}{b V x}-\frac{1}{b}\right],\right. \\
& V x=s \cdot \frac{E_{i}}{E_{i N}} T C V \cdot\left(T-T_{N}\right)+s \cdot V_{\max }-s \cdot\left(V_{\max }-V_{\min }\right) \cdot \exp \left(\frac{E_{i}}{E_{i N}} \cdot \ln \left(\frac{V_{\max }-V_{o c}}{V_{\max }-V_{\min }}\right),\right. \\
& I x=p \cdot \frac{E_{i}}{E_{i N}} \cdot\left[I_{s c}+T C i \cdot\left(T-T_{N}\right)\right], \\
& P(V)=\frac{V \cdot I x}{1-\exp \left(\frac{-1}{b}\right)} \cdot\left[1-\exp \left(\frac{V}{b \cdot V x}-\frac{1}{b}\right)\right],
\end{aligned}
$$

where $P$ is the output power of the photovoltaic panel $(\mathrm{W}), I(V)$ is the output current of the photovoltaic panel (A), $V$ is the output voltage of the photovoltaic(V), $I_{s c}$ is the short-circuit current at $25{ }^{\circ} \mathrm{C}$ and $1000 \mathrm{~W} / \mathrm{m}^{2}, V_{o c}$ is the open-circuit voltage at $25{ }^{\circ} \mathrm{C}$ and $1000 \mathrm{~W} / \mathrm{m}^{2}, V_{\max }$, is the opencircuit voltage at $25{ }^{\circ} \mathrm{C}$ and $1200 \mathrm{~W} / \mathrm{m}^{2}$ (usually, $V_{\max }$ is close to $1.03 . V_{o c}$ ), $V_{\min }$, is the open-circuit voltage at $25{ }^{\circ} \mathrm{C}$ and $200 \mathrm{~W} / \mathrm{m}^{2}$, (usually, $V_{\min }$ is close to 0.85. $V_{o c}$ ), $T$ is the solar panel temperature $\left({ }^{\circ} \mathrm{C}\right), E_{i}$, is the effective solar irradiation impinging the cell in $\mathrm{W} / \mathrm{m}^{2} . T_{w}$ is $25{ }^{\circ} \mathrm{C}$ standard test condition (STC), $T C i$ is the temperature coefficient of $V_{o c}$ in V/C, $I x$ is short circuit current at any given $E_{i}$ and $T, V x$ is open circuit voltage at any given $E_{i}$ and $T ; s$ is photovoltaic panel in series, $p$ photovoltaic panel in parallel. $b$ is characteristic constant based on I-V curve. The characteristic constant, $b$, usually varies from 0.01 to 0.18 and can be calculated using (5) with iterative procedures. 
$b_{n+1}=\frac{V_{o p}-V_{o c}}{V_{o c} \cdot \ln \left(1-\frac{I_{o p}}{I s c} \cdot\left(1-\exp \left(\frac{-1}{b_{n}}\right)\right)\right)}$,

For calculating the available energy of PV array at a specific site which solar radiation profile have shown in Figure. 1, the following equation is used:

$E_{P V}=P_{\text {out }}\left(E_{x}\right) \cdot($ SolarWindow ).(TotalDay $)$,

where $E_{p v}$ is the yearly production of photovoltaic energy in kWh, "SolarWindow" is the total time hours the sun hit the PV module and an average hourly solar irradiation, the product of "TotalDay" is to change from daily to monthly or yearly quantities, $p_{\text {out }}\left(E_{x}\right)$ is the PV module power output at an average hourly solar irradiation $\left(E_{x}\right)$. The $P-V$ and $I-V$ Curves for the proposed solar modules are shown in Figure 2.

TABLE I. SOLAR MODULE SPECIFICATION AT STC

\begin{tabular}{|c|c|c|c|c|}
\hline \multirow{2}{*}{$\begin{array}{c}\text { Type of } \\
\text { PV } \\
\text { module }\end{array}$} & Product & $\begin{array}{c}\text { PV } \\
\text { MSRP } \\
\text { (US\$) }\end{array}$ & $\begin{array}{c}\text { Watt at } \\
\mathbf{1 0 0 0} \\
\mathbf{W} / \mathbf{m}^{2}\end{array}$ & efficiency \\
\cline { 2 - 5 } & & 800 & 200 & 0.2 \\
\hline 1 & $\mathrm{KC} 200$ & 800 & \\
\hline
\end{tabular}

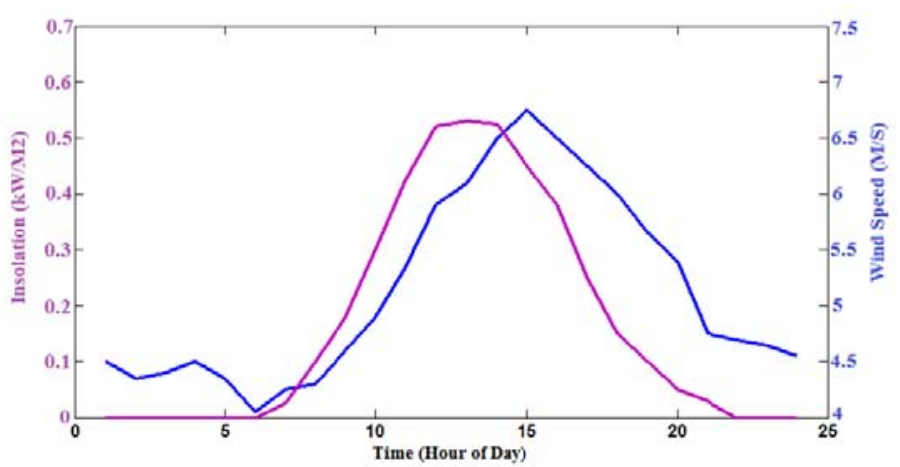

Figure 1. Average hourly wind and insolation profile for Zabol, Iran.
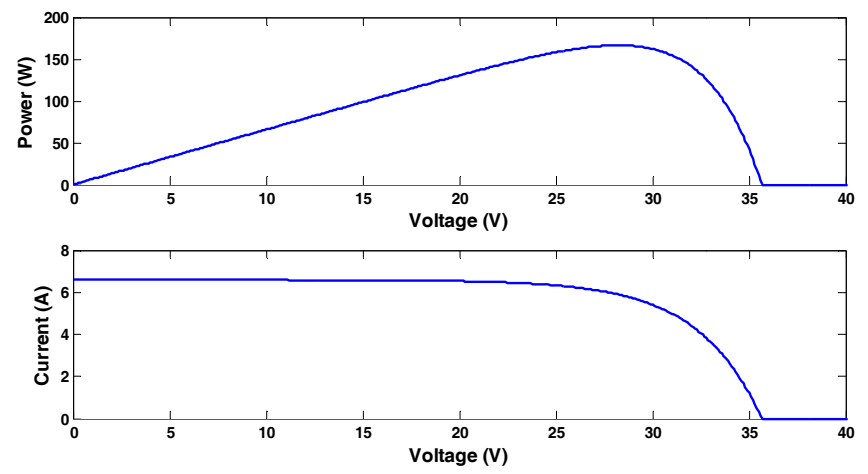

Figure 2. P-V and I-V curve 


\subsection{Model of wind turbine}

Adjusting the measured wind speed to the hub height $(h)$, by using the wind speed data at a reference height $\left(h_{r}\right)$ from the database, is an important phase before calculating the output power of wind turbines. This can be done through the following expression: [14].

$v(t)=v_{r}(t)\left(\frac{h}{h_{r}}\right)^{\gamma}$,

where $v$, is the wind speed at the desired height $h, v_{r}$ is wind speed measured at known height $h_{r}, \gamma$ is wind shear exponent coefficient which varies with pressure, temperature and time of day. Commonly use value for open land is one-seventh (1/7).

Probably density function (pdf) is the best description for variation of wind speed. The pdf calculated the probability that an event will occur between two end points. Note that the pdf curve shape and the height of it provide in some way that the area under the pdf curve from 0 to infinity is exactly 1 . This means that blowing of wind speed will be between 0 and infinity $(\mathrm{m} / \mathrm{s})$. There are various notations for Weibull pdf in papers. In this paper, the Weibull pdf is defined as:

$f(v)=\frac{\beta}{\eta}\left(\frac{v}{\eta}\right)^{\beta-1} e^{-\left(\frac{v}{\eta}\right)^{\beta}}$

where $\beta$ is the shape factor and $v$ is wind speed. The smaller shape factor show that the distribution of wind speed is near the average. The scale factor $(\eta)$ shows how the distribution lies and how it stretched out. For wind speed profile which shown in Figure 1, the Wiebull probability distribution function has shown in Figure 3.

The output power of wind can be calculated by using probability distribution function for a specific site. The output energy can estimate by using wind turbine power curve. The wind turbine power curve which usually given by manufacturer shows the output power of wind turbine at any wind speed. The available energy for a wind speed profile can be calculated as:

$E_{W T}=($ days $)($ hours $) \sum_{v=1}^{25} P_{c} f(v, \beta, \eta)$

where $E_{w t}$ is the generated energy of wind turbine in $\mathrm{kWh}$ for a specific site. The product of days and hours gives the total hours in the period of simulation, $P_{c}$ is the output power of wind turbine, $f(v)$ is the Weibull pdf for wind speed $v, \beta$ is the shape factor and $\eta$ is scale factor. It has been used "Whisper 100" small wind turbine type in this simulation which its power curve given by manufacture, is shown in Figure 4. The total wind turbine energy output for one year for the proposed wind turbine is shown in Figure 5. 
M. A. Yazdanpanah Jahromi, S. Farahat, S. M. Barakati / TJ MCS Vol .5 No. 2 (2012) 134-145

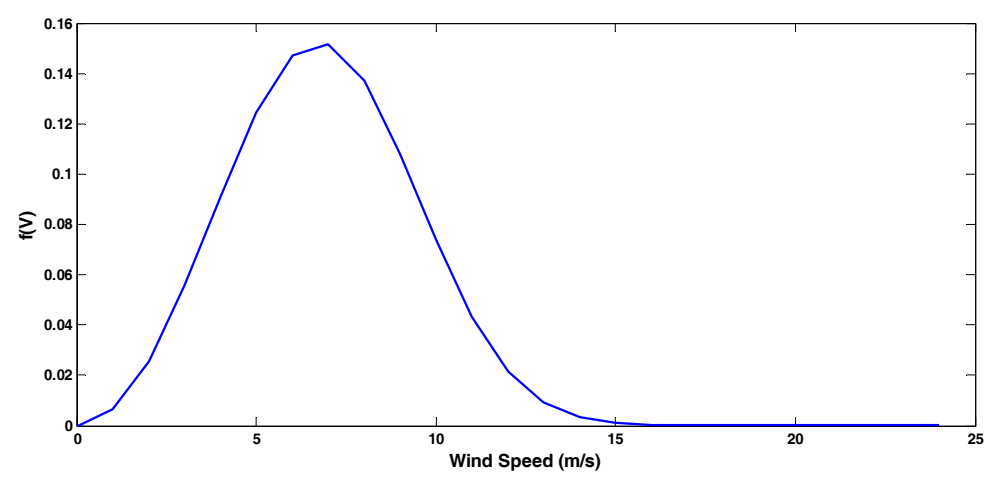

Figure 3. Weibull probability density function (f(v))

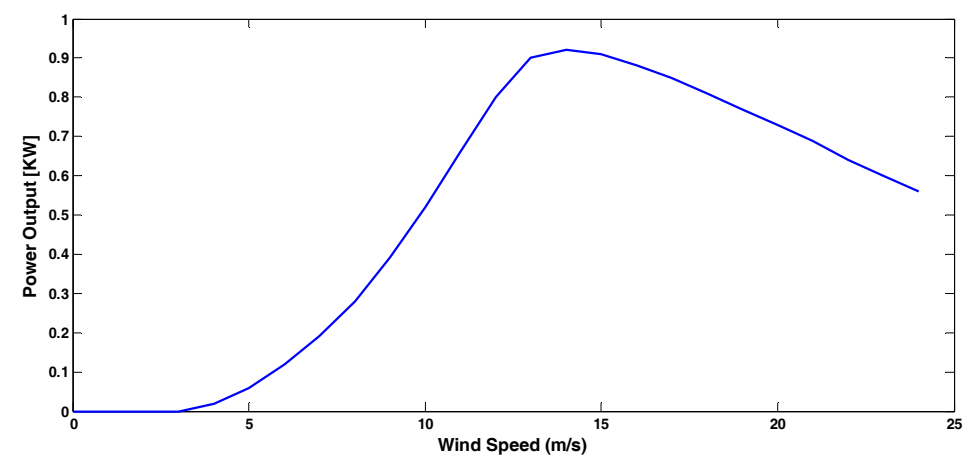

Figure 4. Power curve for wind turbine "Whisper 100"

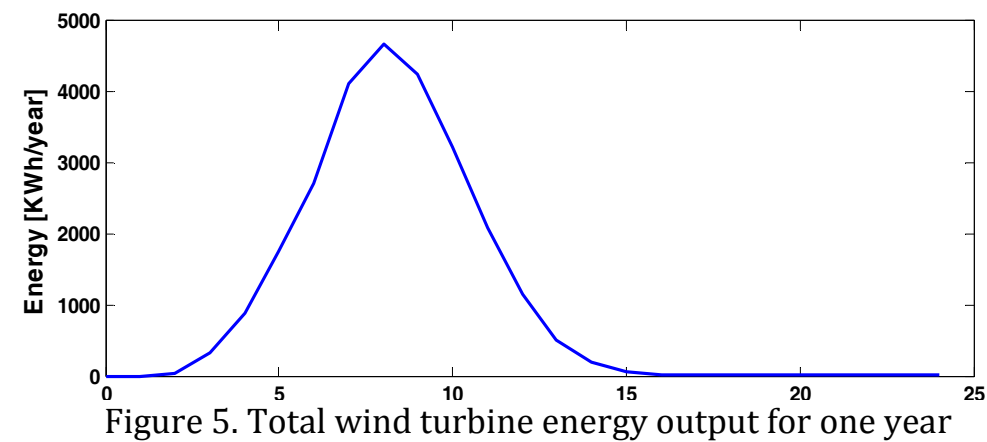

\subsection{Load model}

The hourly load data used in this simulation for one year is shown in Figure 6. This is the yearly variation of domestic load profile in the proposed region. 


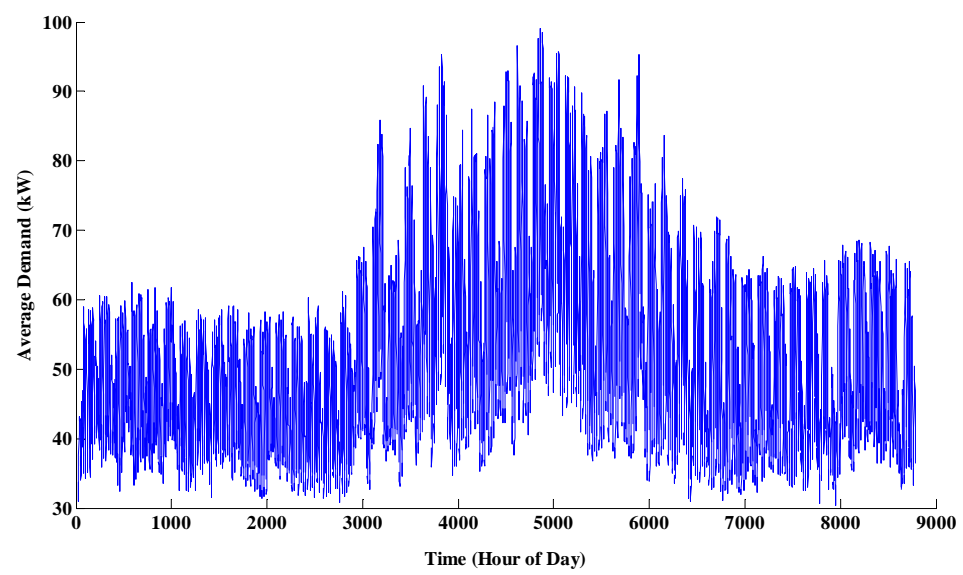

Figure 6. Daily variation of domestic load profile for one year in Zabol

\section{Electricity match criteria of hybrid systems}

Matching of electricity generation and consumption over a predefined period is an important task in hybrid power systems. The higher match rate between supplies and demand gives the lower investment. For quantifying the deviation between two set of data variables, the least squares (LS) approach can be used. The following equation describes LS [15]:

$L S=\sum_{t=0}^{n}\left(D_{t}-S_{t}\right)^{2}$

The LS can change in range of 0 to infinity. The lower LS show the higher match rate between two set of proposed variables. The value of zero for LS shows a perfect match. Spearmam's Rank correlation coefficient (CC) can describe the correlation between supply and demands. CC can vary from -1 to 1 . Closer CC to 1 and -1 gives the better match rate. "1" shows the perfect positive match and "- 1 " shows perfect negative match where "0" represents no match. The CC can express as follows [15]:

$C C=\frac{\sum_{t=0}^{n}\left(D_{t}-d\right) \cdot\left(S_{t}-s\right)}{\sqrt{\sum_{t=0}^{n}(D t-d)^{2} \cdot \sum_{t=0}^{n}(S t-s)^{2}}}$,

where $D_{t}$ is the demand and $S_{t}$ is the supply at time $\mathrm{t}, \mathrm{d}$ and $s$ are demand and supply average aver time period $\mathrm{n}$, respectively. The higher $\mathrm{CC}$ gives more electricity match rate between supplies and demand.

Inequality coefficient (IC) is another objective function which can be ideally used to describe match rate. This objective defines the inequality in time-series due to three sources: unequal tendency (mean), unequal variation (variance) and imperfect co-variation (co-variance) [15].The smaller IC, 
M. A. Yazdanpanah Jahromi, S. Farahat, S. M. Barakati / TJ MCS Vol .5 No. 2 (2012) 134-145

give us the larger match rate. IC can vary in range of 0 to 1 . It can be given by the following equation [16]:

$$
I C=\frac{\sqrt{\frac{1}{n} \sum_{t=0}^{n}\left(D_{t}-S_{t}\right)^{2}}}{\sqrt{\frac{1}{n} \sum_{t=0}^{n}\left(D_{t}\right)^{2}}+\sqrt{\frac{1}{n} \sum_{t=0}^{n}\left(S_{t}\right)^{2}}}
$$

Value of IC between 0-0.4 shows good matches and value above 0.5 represents bad match [16]. IC is a better criterion for determining the match rate. However CC is also good but it is not as well as IC.

\section{Optimization procedure Using NSGA-II}

Sizing of the hybrid power generation systems is much more complicated than the single source power system. Maximization of CC and also IC minimization are the two objectives of this optimization procedure for hybrid Wind/PV power system. These objectives are conflicting to each other. In order to reach the best compromise of IC and CC, long-term system performance is required. By employing the NSGA-II algorithm to the proposed hybrid power system, a set of optimal solutions are obtained.

Implementation of NSGA-II in various engineering and business applications have been done in recent years. This multi-objective optimization algorithm can find Pareto-optimal solution in one single simulation run. NSGA-II uses a fast non-dominated sorting approach and also an elitist strategy. Diversity is presented by using crowded comparison criterion in the tournament selection and in the phase population reduction [17]. A good sizing algorithm is the one which can find the optimal sizing of each component ( $\mathrm{n} 1$ and $\mathrm{n} 2$ ) to maximize the electricity match rate between supply and demand. " $\mathrm{n}_{1}$ and $\mathrm{n}_{2}$ " are design variables which define the number of PV panels and wind turbine, respectively. The minimum value (lower limit) of design variables is selected 1 to be sure that there is at least one of each supply in system. The flow chart of the algorithm is shown is Figure 7. 


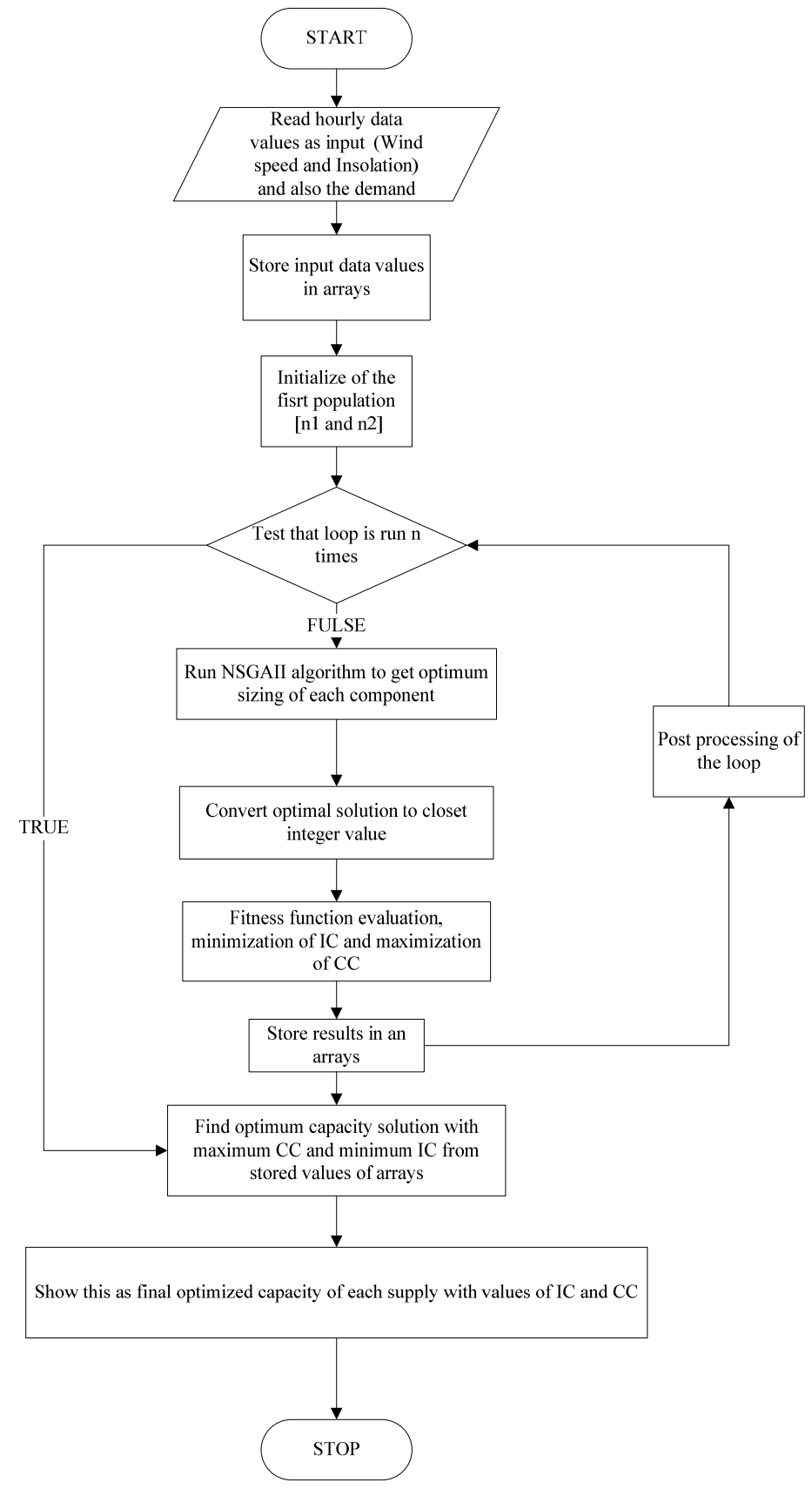

Figure 7. The scheme of optimization using NSGA-II

\section{Results}

The sizing of optimal hybrid Wind/PV systems was achieved using multi-objectives optimization algorithm (NSGA-II) approach. Results appear as an optimal Pareto front. Each solution of the best Pareto front was found by a combination of hybrid systems in somehow to have higher electricity match rate. The inequality coefficient (IC) and the correlation coefficient (CC) were computed for each combination. Figure 8 shows the optimal Pareto front between IC and CC. It can be noted that the improvement of IC implies the decreasing of the CC.

TABLE. II gives the optimal size of devices and the computed IC and CC objectives at these optimal sizes. The optimization process dynamically searches the optimal configuration to minimize the IC 
M. A. Yazdanpanah Jahromi, S. Farahat, S. M. Barakati / TJ MCS Vol .5 No. 2 (2012) 134-145

and maximize the CC. As said before, in order to have good electricity match rate, IC values must be as low as possible. The values lower than 0.4 are acceptable for providing good match rate between supplies and demand. Higher CC is another criterion for this process. The Pareto front has plotted for IC and CC which obtained curve is shown in Figure 8. When a pre-specified iteration count $\left(\mathrm{N}=\mathrm{N}_{\max }\right)$ is reached, NSGA-II is terminated. $\mathrm{N}_{\max }=50$ and a population size of $\mathrm{N}_{\text {pop }}=50$ are used. The probability of crossover and mutation are 0.9 and 0.1 used for this optimization. The 4 best sizing selections from 30 runs for best configuration has been obtained and rounded to the nearest integers greater than or equal to them. These results show that the optimal size of wind turbine is "1" in all case and the number of PV generators can be "1,2,3 or 4" with the IC and CC values shows in Table II. The obtained results show good electricity match rate between supplies and demand. This optimization process helps to have lower investment with higher reliability. The selection of each configuration is depending on the economical criteria which can be another objective function in optimization procedure for future work.

TABLE II. PARETO FRONT/OPTIMAL SOLUTIONS OBTAINED FROM MULTI OBJECTIVE OPTIMIZATION

\begin{tabular}{|c|c|c|c|c|}
\hline Solution & \multicolumn{4}{|c|}{ Optimization Algorithm made in NSGA-II } \\
\cline { 2 - 5 } Number & $\boldsymbol{I C}$ & $\boldsymbol{C C}$ & $\boldsymbol{N}_{\boldsymbol{P V}}$ & $\boldsymbol{N}_{\boldsymbol{W I N D}}$ \\
\hline 1 & 0.2521 & 0.9443 & 2 & 1 \\
\hline 2 & 0.0513 & 0.9479 & 1 & 1 \\
\hline 3 & 0.1684 & 0.9504 & 3 & 1 \\
\hline 4 & 0.3690 & 0.9531 & 4 & 1 \\
\hline
\end{tabular}

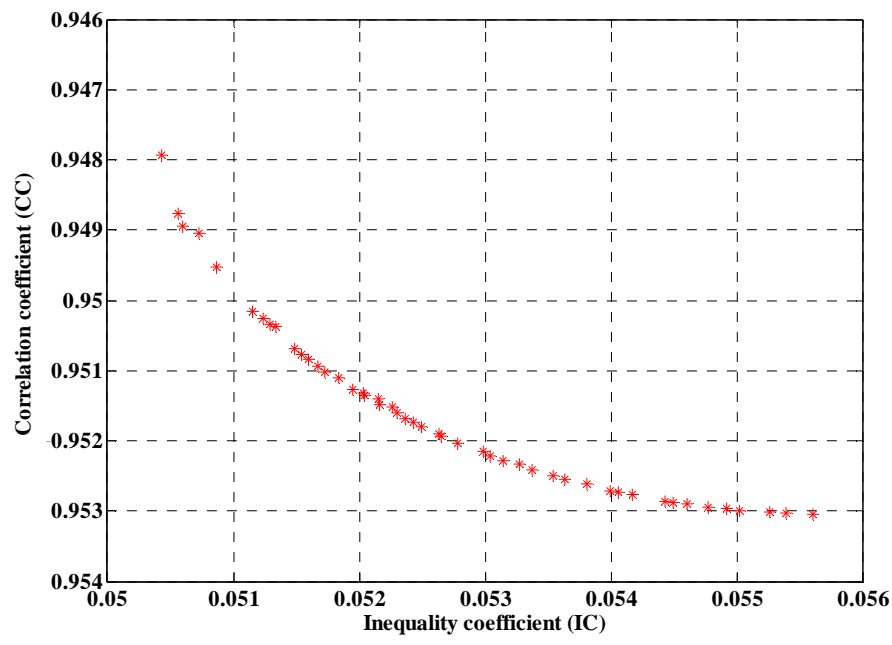

Figure 8. Obtained NSGA-II solution for the IC and CC

\section{Conclusion}

In order to utilize hybrid renewable energy systems more efficiently and economical, a new optimum sizing method is developed in this paper. The main objective of the present method is to estimate the optimum size of a stand-alone hybrid power system able to accomplish the load energy requirements economically. In this setting, a multi-objective optimization algorithm based on non-dominated sorting genetic algorithm (NSGA-II) is developed according to the mathematical models and optimization criteria. Maximization of electricity match rate between supplies and 
M. A. Yazdanpanah Jahromi, S. Farahat, S. M. Barakati / TJ MCS Vol .5 No. 2 (2012) 134-145

demand can improve reliability, efficiency and at the same time, decrease the economic cost. Inequality coefficient (IC) and correlation coefficient (CC) are the main objectives for checking the electricity match rate. The collected solar radiation, temperature and wind speed data in the site of Zabol, located in Sistan and Baluchestan, Iran, was used in this study. The application of the methodology has allowed determining several solutions which are presented under optimal Pareto front form. The optimum configuration satisfies the load demand with minimum inequality coefficient (IC) and maximum correlation coefficient (CC). The number of wind turbine in all solution is " 1 " and the number of PV panels can be " $1,2,3$, or 4 " by considering the economic criteria. The results demonstrate the practical utility of the new proposed methodology.

\section{References}

[1] Mehdi Vafaei, "Optimally-Sized Design of a Wind/Diesel/Fuel Cell Hybrid System fo Remote Community " Master of Applied Science Electrical and Computer Engineering University of Waterloo, 2011.

[2] Daming $\mathrm{Xu}$, Longyun Kang, Liuchen Chang, and Binggang Cao, "Optimal Sizing of Standalone Hybrid Wind/PV Power Systems Using Genetic Algorithms" presented at the IEEE, May 2005.

[3] Hongxing Yang, Wei Zhou, Lin Lu a, and Z. Fang, "Optimal sizing method for stand-alone hybrid solar-wind system with LPSP technology by using genetic algorithm," Solar Energy, ELSEVIER, pp. 354-367, 2008.

[4] Zhou Wei, "Simulation and Optimum Design of Hybrid Solar-Wind and Solar-Wind-Diesel Power Generation Systems,", Doctor of Philosophy, The Hong Kong Polytechnic University,, 2007.

[5] D.B. Nelson, M.H. Nehrir, and C. Wang, "Unit sizing and cost analysis of stand-alone hybrid wind/PV/fuel cell power generation systems," Renewable Energy, ELSEVIER, pp. 1641 - 1656, 2006.

[6] Zhou Wei and Yang Hongxing, "One Optimal Sizing Method for Designing Hybrid Solar-WindDiesel Power generating Systems"presented th the Zhou Wei, Yang Hongxing 2007.

[7] D.B. Nelson and M.H. Nehrir, "Unit Sizing of Stand-Alone Hybrid Wind/PV/Fuel Cell Power Generation Systems," IEEE, pp. 1-7, 2005.

[8] B. Ould. Bilala, V. Samboua, C.M.F Kébé, P. A. Ndiaye, and M. Ndongo, "Methodology to Size an Optimal Stand-Alone PV/wind/diesel/battery System Minimizing the Levelized cost of Energy and the CO2 Emissions " Energy Procedia, ELSEVIER, pp. 1636 - 1647, 2012.

[9] R. Luna-Rubio, M. Trejo-Perea, D. Vargas-Va'zquez, and G.J. Ri'os-Moreno, "Optimal sizing of renewable hybrids energy systems: A review of methodologies," Solar Energy, ELSEVIER, pp. 10771088,, 2012.

[10] Y. S. Zhao, J. Zhan, Y. Zhang, D. P. Wang, and B. G. Zou, "The Optimal Capacity Configuration of An Indepebdent Wind/PV Hybrid Power Supply System Based on Improved PSOAlgorithm", 2006.

[11] Javed Dhillon, "Multi objective Obtimization of Power Dispatch Problem Using NSGA-II", Master of Engineering Power Systems \& Electric Drives, Thapar University, Patiala, 2009.

[12] Rodolfo Dufo-Lopez and Jose' L. Bernal-Agustin, "Multi-objective design of PV- wind- dieselhydrogen- battery systems," Renewable Energy, ELSEVIER, pp. 2559- 2572, 2008.

[13] Miguel Rios Rivera, "Small Wind/Photovoltaic Hybrid Renewable Energy System Optimization" Master of Science, Electrical Engineering, Puerto Rico, Mayagüez Campus, 2008. 
M. A. Yazdanpanah Jahromi, S. Farahat, S. M. Barakati / TJ MCS Vol .5 No. 2 (2012) 134-145

[14] Eftichios Koutroulis, Dionissia Kolokotsa, Antonis Potirakis, and Kostas Kalaitzakis, "Methodology for optimal sizing of stand-alone photovoltaic/wind-generator systems using genetic algorithms," Solar Energy, ELSEVIER, pp. 1072-1088, 2006.

[15] Francesca Jane Born, "Aiding Renewable Energy Integration through Complimentary DemandSupply Matching," Doctor of Philosophy, Energy Systems Research Unit, University of Strathclyde, 2001.

[16] Sana Waqas, "Development of an Optimisation Algorithm for Auto sizing Capacity of Renewable and Low Carbon Energy Systems ," Master of Science , , Department of Mechanical Engineering,, University of Strathclyde Engineering,, 2011.

[17] Daming Xu, Longyun Kang, and Binggang Cao, "The Elitist Non-dominated Sorting GA for Multiobjective Optimization of Standalone Hybrid Wind/PV Power Systems," Applied Sciences, 2006. 